\title{
AS FRONTEIRAS ENTRE FICÇÃO E HISTÓRIA EM PALHA DE ARROZ, DE FONTES IBIAPINA
}

The frontiers between ficction and history in Palha de Arroz, by Fontes Ibiapina

Enéias Napoleão Araújo Brasil ${ }^{1}$

RESUMO: Este estudo tem por objetivo expor os limites e convergências entre ficção e história como caminhos esclarecedores para compreensão de um determinado contexto social e histórico. Tomaremos como objeto o romance Palha de Arroz, de Fontes Ibiapina, buscando relacionar algumas passagens com o contexto histórico nacional sobre o qual ele foi construído: a ditadura de Getúlio Vargas. O narrador em Palha de Arroz emerge como símbolo de uma voz coletiva que abriga os amplos discursos de um contexto social esquecido pela memória oficial. A partir da obra, é possível sinalizar que seu narrador cumpre uma função de religar os eixos entre ficção e história, demonstrando que os mesmos não se constituem distantes.

Palavras-chave: Ficção. História. Memória.

ABSTRACT: This study aims to expose the limits and convergences between fiction and history as enlightening ways to understand a determined social and historical context. We will take as object the novel Palha de Arroz by Fontes Ibiapina, seeking to relate some passages with the national historical context on which it was built: the Getúlio Vargas dictatorship. The narrator in Palha de Arroz emerges as a symbol of a collective voice that shelters the broad discourses of a social context forgotten by the official memory. From the work, it is possible to signal that its narrator fulfills a function of reconnecting the axes between fiction and history, demonstrating that they are not distant.

Keywords: Fiction. History. Memory.

\section{INTRODUÇÃO}

Ficção e História: uma dicotomia que pode gerar uma série de questionamentos acerca do que pode ser ou não "verossímil" ou ainda "verdadeiro"; uma preocupação que retorna à baila quando se trata de analisar as fronteiras existentes entre cada "categoria". Ficção e História poderiam e deveriam andar

\footnotetext{
${ }^{1}$ Mestrando em Letras (UESPI). E-mail: eneiasbrasil@gmail.com

Cadernos Cajuína, V. 3, N. 2, 2018, p. 14 - 25.
}

ISSN: 2448-0916 
juntas, seria uma forma consistente de propor uma diluição dessa discussão entre o que pode ser considerado ficção e o que pode ser considerado história. O presente estudo tem por objetivo expor aspectos referentes aos limites e convergências entre termos aparentemente opostos, mas que se encarados por um prisma englobante, podem oferecer caminhos mais elucidativos perante essa instigante discussão. Para isso, tomaremos como objeto o romance Palha de Arroz, de Fontes Ibiapina, buscando relacionar algumas passagens com o contexto histórico nacional sobre 0 qual ele foi construído: a ditadura de Getúlio Vargas.

Considerado uma obra prima, Palha de Arroz é um romance considerado histórico-documental, no qual temos o retrato da cidade de Teresina da década de 40 e seus problemas de saneamento básico, falta de energia elétrica, pobreza e descaso público para com a população suburbana (principalmente nos bairros à margem do Parnaíba). Uma população desassistida e sem perspectiva de vida emerge desse espaço e o cotidiano é pincelado de maneira caricatural na obra, trazendo aspectos como a promiscuidade daquele meio social expressa, inclusive, pela denominação dos cabarés (Pau Não Cessa, Curral das Éguas, etc.); pelo retrato dos bêbados, "pescadores de defuntos", prostitutas, estivadores e delinquentes de todo tipo.

\section{O NARRADOR COMO VOZ COLETIVA}

Um elemento central abordado na obra são os históricos incêndios criminosos acontecidos na cidade na década de 40 atendendo a uma espécie de política de "limpeza social". Em plena Era Vargas e II Guerra Mundial (mesmo que na obra grande parte da população não tivesse exatamente noção do momento histórico) é patente na narrativa a constante sensação de insegurança pungida aos personagens, principalmente, através de bilhetes ameaçadores assinados sob as iniciais X. P. T. O., bem como através do clima de medo e repressão imposto pela polícia que, em certa altura da narrativa, punia os moradores que tentassem entrar nas casas em chamas para salvar alguns de seus pertences. Nota-se, portanto, uma organização sólida e profunda de atos concatenados com o objetivo claro de limpeza social. 
Palha de Arroz subindo na fumaça. Palha de Arroz se indo. Também... pudera! Um subúrbio imundo bem no centro da cidade. $\mathrm{Se}$ ao menos noutra cidade qualquer! Mas, a Capital? Que impressão teriam do Piauí os turistas que por ali passavam?! Que sairiam pensando de nosso povo?! De nossa terra?! De nossa cultura?! De nosso progresso?! Quando acaba, diretamente prejudicado só foi mesmo quem quis. Como de sempre, o célebre bilhete do aviso-prévio amanheceu no batente da porta principal de uma das casas - aliás, da Pensão Alegre - '14 Bandas'.

- Vai hoje haver incêndio neste bairro. Quem não quiser ser prejudicado que trate, enquanto é tempo, de retirar os cacarecos e demais pertences

“as) X. P. T. O.”(IBIAPINA, 2007, p. 32)

No fragmento aqui transcrito é possível perceber uma série de pontos elucidativos no tocante ao clima de terror do qual a população da região suburbana era vítima. O narrador constrói essa passagem com tons de ironia e deboche na medida em que qualifica o bairro Palha de Arroz como um "subúrbio imundo bem no centro da cidade". Sendo a Capital, a cidade não deveria mais abrigar pessoas tão desprovidas de tudo, inclusive de cultura "formal" e progresso, sobre os quais o narrador reflete de forma irônica ao intencionar exatamente o contrário: uma comunidade desassistida como Palha de Arroz e tantas outras, que não dispõem das necessidades básicas, como evidenciar a cultura? Como uma comunidade como essas retratadas na obra em estudo podem ser símbolos de progresso? Justamente aí reside a crítica empreendida pelo narrador: a de que uma cidade como a Teresina da década de 40 não tinha condições de ser exemplo de cultura e progresso. A organização política da época se constituía como uma sabotagem a si mesma com propósitos escusos de luta de poderes políticos: a oposição política que começava a se formar contra a Polícia, simbolizada na personagem Juliano, jornalista do jornal O Piauí "jornal pequeno mas de língua de légua e meia" (p. 29) que procurava acusar o chefe policial de promover os atos de "limpeza social" atendendo a ordens superiores.

Os liames entre ficção e história no romance analisado se fundem em um jogo de histórias sobre a vida dos personagens miseráveis do subúrbio de Teresina. Aqui classificamos como "causos" contados pelo narrador que evoca, com o transcorrer da narrativa, vários enfoques de vidas: todas miseráveis, banais, sem esperança de modificação de estrato social. Vale ressaltar o papel do narrador que 
se posta como uma figura que documenta aquela realidade, encurtando a distância entre ficção e realidade (história). Podemos postular, portanto, que o narrador de Palha de Arroz pode ser considerado, segundo Jeanne Marie Gagnebin, como um "narrador sucateiro".

Esse narrador sucateiro (...) não tem por alvo recolher os grandes feitos. Deve muito mais apanhar tudo aquilo que é deixado de lado como algo que não tem significação, algo que parece não ter nem importância nem sentido, algo com o que a história oficial não saiba 0 que fazer (GAGNEBIN, 2001, p. 90).

Podemos afirmar, assim, que o narrador do romance em estudo cumpre uma função que converge os conceitos de ficção e história na medida em que sustenta um papel de documentação de uma história não oficial - constitui-se, esse narrador, como "guardião" da história vivida por um povo miserável que não foi registrada pela história oficial: a aflição e abandono daquela população pobre à mercê do descaso público, o evidente abandono por parte das autoridades das regiões suburbanas da cidade, o relato de torturas e trabalhos forçados de que eram vítimas muitos moradores da periferia, dentre outros aspectos. Tendo como pano de fundo os incêndios criminosos em Teresina na década de 40, fato que ficou marcado como episódio vergonhoso na história piauiense, a narrativa se consolida como uma voz de uma população impotente diante das calamidades promovidas pelo estado. São episódios traumáticos em que a repressão por parte da Polícia forçaria os habitantes a um "esquecimento forçado", ao silêncio necessário para que se mantivesse uma aparente "ordem".

Michael Pollak, em seu "Memória, Esquecimento, Silêncio" constrói um argumento que pode ilustrar com suficiência a sobreposição de história oficial $x$ história não oficial:

Em face dessa lembrança traumatizante, o silêncio parece se impor a todos aqueles que querem evitar culpar as vítimas, que compartilham essa mesma lembrança 'comprometedora', preferem, elas também, guardar silêncio. Em lugar de se arriscar a um mal-entendido sobre uma questão tão grave, ou até mesmo de reforçar a consciência tranquila e a propensão ao esquecimento dos antigos carrascos, não seria melhor se abster de falar? (POLLAK, 1988, p. 6). 
É possível afirmar que o interesse da história oficial seria ofuscar episódios que maculariam a imagem do Estado na medida em que duas memórias entram em disputa: a oficial (manipulada, podada) e a não oficial (encontrada nos discursos da população em geral ou "documentada" em obras literárias). É válido ressaltar, portanto, que a história não oficial permanece conservada nos círculos orais, na literatura (considerada simplesmente como ficção, por isso muitas vezes invalidada como documentação histórica), passando de geração em geração, até que chegue o momento de ela vir à tona e se "oficializar", quando o tempo já tiver decorrido o suficiente para não trazer consequências ao Estado - quando tudo se resumirá à "memória esquecida".

O longo silêncio sobre o passado, longe de conduzir ao esquecimento, é a resistência que uma sociedade civil impotente opõe ao excesso de discursos oficiais. Ao mesmo tempo, ela transmite cuidadosamente as lembranças dissidentes nas redes familiares e de amizades, esperando a hora da verdade e da redistribuição das cartas políticas e ideológicas. (POLLAK, 1988, p. 5)

O narrador em Palha de Arroz cumpre pontualmente esse papel de "guardador da história", configura-se como conservador dessa realidade esquecida e desprezada pelos discursos oficiais. O romance em estudo mesmo sendo considerado como ficção pode ser importante instrumento de compreensão histórica diminuindo as fronteiras tênues entre ficção e história.

\section{FICÇÃO E HISTÓRICA: INTERSEÇÕES}

A narrativa se constrói tendo como tempo a ditadura de Getúlio Vargas, como já mencionado anteriormente. Através desse momento histórico nacional é possível fazer em várias passagens do romance mais relações convergentes entre ficção e história, uma vez que são levantados aspectos referentes às consequências da ditadura na sociedade teresinense da década de 40: repressão, manipulação de dados oficiais, "limpeza social" e outras medidas atendendo a interesses ditatoriais daquele contexto histórico. A repressão tendia a ser cada vez mais intensa e, como mencionado anteriormente, até os próprios moradores pobres passaram a ser impedidos de salvar seus poucos pertences, bem como passaram a ser vigiados 
como uma tentativa de atribuição de culpa pelos incêndios promovidos pelo próprio Estado; tratava-se de uma postura de fuga de responsabilidades, na medida em que o próprio governo promovia as atrocidades e culpabilizavam os próprios moradores pobres, impotentes diante daquele limitado contexto social. É o que percebemos no seguinte trecho:

Não era dizer que os incêndios tivessem tido seu fim. Mas se dava que, dentro de casa se queimando, nem ele nem ninguém podia cruzar os pés. Lei da Polícia. Era só o que faltava! Polícia decretando lei... E ai daquele que a deixasse de cumprir. Ai daquele! Nem as próprias pessoas da casa tinham direito de tirar ao menos um cacareco. Triste daquele que tentasse salvar algo (IBIAPINA, 2007, p. 82).

Nessa altura da narrativa e a partir do trecho acima é possível perceber que a repressão se intensifica e a perseguição à população marginal aumenta. Aquele que desobedecesse sofreria fortes consequências como trabalho forçado e torturas variadas ao ser levado para a construção de um prédio no bairro llhotas sobre o qual o narrador, em digressão temporal, tece comentários sobre quando o personagem Pau de Fumo, ao desobedecer à ordem oficial, foi levado para aquele campo de trabalho.

[...] foi bater com os costados nas Ilhotas. Servição pesado. De sol a sol. E, vez por outra, um banho de acoites. Pontapés. Puxavantes de orelha. Servição pesado ajudando a construir aquele prédio. Aquele mesmo que agora era uma Escola de Menores Abandonados. (Escola de Menores... Que tal?! Tem graça! Os pobres e coitados meninos apanhando a três por quatro. E em trabalho forçado. Sofrendo que nem sovaco de aleijado) (IBIAPINA, 2007, p. 83).

Outro indício da intensidade da repressão oficial na narrativa foi a proibição por parte das autoridades do termo incêndio. Quem fosse colhido falando sobre o referido termo ou sobre seus correlatos como "fogo" seria preso como suspeito de promover os incêndios criminosos. Assim a população, reprimida, passou a dizer "chuva". "Quem gritasse incêndio seria preso. Daí o povo passou a dizer chuva. (...) qualquer um que dissesse incêndio iria direto para as grades" (p. 87). Eis aqui mais um ponto de convergência entre ficção e história: a repressão de determinados termos por parte do regime ditatorial com a finalidade de manter a "ordem oficial": se não houvesse notícias sobre os crimes, eles oficialmente deixariam de existir. 
É útil ressaltar que a obra Palha de Arroz revela um narrador que se constitui como crítico daquilo que narra na medida em que "assume", por assim dizer, diversos enfoques perceptivos. Em determinadas passagens, o narrador emite comentários, como se tentasse fazer uma análise crítica daquilo que está narrando. Por vezes, mas sem deixar-se revelar-se plenamente, constrói críticas pontuais sobre aquele contexto sobre o qual se desenvolve a narrativa. É o que podemos observar no trecho a seguir,

- Diabo! Pra que estudei!?... Só pra saber tantas coisas que só me dão preocupações. Preocupações e revolta. (Revolta e ódio).

Se a Fiação estivesse em movimento, não havia tanta gente com fome em Teresina, tanta gente sofrendo necessidades no Piauí, mesmo em regime de força, Ditadura como era, mas, havendo pão e pano, estaria tudo bem. Até que ele mesmo não era contra aquele governo ditatorial. Não era contra aquela Ditadura em si. Era um caso de necessidade. Naquela guerra maluca, não seria possível um país se preocupar com eleições. Detestava apenas a miséria que se via por aí. Podia ser ao menos como diziam os escravagistas nos tempos da campanha da Abolição da Escravatura: - o povo precisa de três coisas em P (PPP): pau, pano e pão.

- (Que anacronismo! E saúde?! E educação?! Intelectuais obsoletos!) (IBIAPINA, 2007, p. 73).

A partir de uma costumeira reflexão de Pau de Fumo sobre o mundo imediato que o cerca, o narrador desfaz seu discurso, porém deixa transparecer a compreensão da visão tolhida da personagem que não tem escolha, uma vez que Pau de Fumo, por questões de "necessidade" apenas se preocupa com o atendimento de suas necessidades básicas. A desconstrução realizada pelo narrador se dá na intromissão crítica que ele realiza ao reivindicar saúde, educação e classificar os intelectuais escravagistas como obsoletos ao adotarem o discurso das "três coisas em P". O narrador busca nessa passagem ampliar a problemática do negro/pobre marginalizado na medida em que postula a necessidade da população desassistida de ter condições mínimas de dignidade social: em outras palavras, há mais uma convergência entre ficção e história quando o narrador aproxima duas realidades aparentemente distantes (ditadura e escravidão), concordantes no tocante à marginalização do pobre e do escravo, na figura do protagonista, em que ele se enxerga sem perspectivas e continuando "cativo" da situação social. 
Palha de Arroz apresenta outro recurso de aproximação entre Ficção e História quando o narrador traz, na voz da personagem Pau de Fumo, referências ao pensamento ocidental. Para exemplo, selecionamos o trecho a seguir quando o personagem dialoga com seu melhor amigo, Negro Parente:

- Você não sabe de nada. Não estudou! Olhe, negro velho, eu fui estudante não foi só de ginásio, não. Li quase toda aquela biblioteca do Estado. Se eu fosse explicar pra você o que sei sobre a Origem das Espécies, com base em Darwin e Haekel, você ficaria até doido. Li e reli A Ética e A Política de Aristóteles - para mim, o maior de todos eles. Também A República de Platão (...) Estudei Spinoza que, partindo de definições e postulados fundamentais (baseado em Descartes), chega a construir um verdadeiro edifício de deduções sociológicas, intelectuais e científicas. Li Comte, Eça de Queirós, Vítor Hugo e tantos outros (...) (IBIAPINA, 2007, p.75-76).

Percebemos, portanto, um recurso que rompe os limites entre ficção e história na medida em que a fala do personagem referencia pensadores da história da humanidade como Platão, Aristóteles e Descartes. Nesse trecho, é patente a íntima relação do mundo externo (realidade) com o mundo interno (obra), comprovando assim nossa proposição do link mencionado entre realidade e ficção. Ainda sobre isso, diz Silva:

Em Palha de Arroz o autor utiliza alguns pontos de referência ou de ligação histórica (...) São elementos históricos secundários que, ao se relacionarem ao fato histórico principal, darão autenticidade ao mesmo de forma dupla, tendo em vista que eles, ao serem colocados no contexto histórico concreto, caracterizam o discurso histórico e, ao serem usados no discurso literário, atribuem-lhe uma expressão realista (SILVA, 2002, p. 220).

Os sinais de "realidade" no transcorrer da obra são referenciados principalmente nas reflexões de Pau de Fumo. Silva assevera que esses pontos de convergência entre história e ficção caracterizam discurso histórico constituindo, em nossa observação, uma espécie de relação autêntica entre a obra literária e mundo real. Como já observado, há muitas passagens em que esse link é executado. Podemos selecionar para exemplo mais uma fala de Pau de Fumo:

A gente só aguenta calado porque é o jeito. Infelizmente, estamos em Ditadura. Felizmente também, apesar de tudo, já se fala em Democracia. (...) você é porque não estudou. Não sabe o que 
significa governo de fato, despótico, arbitrário, de força. (...) (IBIAPINA, 2007, p. 96).

É possível perceber no trecho acima uma reflexão feita por Pau de Fumo, dialogando mais uma vez com o amigo Parente, sobre o momento histórico sobre o qual a narrativa é construída (para reiteração, década de 40 em plena Ditadura Vargas). Nota-se, também, que nesse momento da narrativa o protagonista apresenta um amadurecimento de ideias diante dos fatos ocorridos na comunidade: Pau de Fumo é um personagem inteligente e crítico, que estudou no Colégio Diocesano, leu muito enquanto pôde, mas por força de sua condição social e racial não conseguiu oportunidades de ascensão. Esse espírito questionador continuaria mais vivo do que nunca, porém não encontrava válvula de escape, o personagem acreditava que não adiantava ter estudado tanto se não tinha condições ou oportunidades de transformar a própria realidade. Parcas tentativas de mudança eram empreendidas pela personagem, mas ele acabava voltando à condição de miséria moral sendo impelido a roubar para sobreviver.

O amadurecimento crítico pelo qual passa Pau de Fumo pode ser expresso pela passagem aqui selecionada:

- Que jeito! Mesmo assim, o que adianta! Pra que mais que estudou Pau de Fumo. Agora mesmo, depois que anda por aí metido a carregador, toda folgazinha que tem vai ler lá na Biblioteca. Parece que deixa até de trabalhar pra ler. (...) (IBIAPINA, 2007, p. 119).

Essa é uma fala de Antonino, filho do melhor amigo de Pau de Fumo, Negro Parente. O menino em conversa com o pai expressa seu desejo de ser "pescador de defuntos" como fora o pai, mas Parente o incentiva a aprender a ler para ter condições de um dia mudar de vida. Antonino assevera que aprender a ler não traz nada a ninguém, que Pau de Fumo, mesmo com leitura, não conseguira nada na vida. No discurso do menino, é possível perceber que Pau de Fumo, agora Chico da Benta, estava lendo mais intensamente após deixar a vida de roubos:

Mas quem dormia em sua casa era Pau de Fumo. Hoje sou Chico da Benta. Pau de Fumo morreu no meio da rua, por cima duma chapa de carregador. E Chico da Benta nasceu com uma chapa de carregador nas mãos. (IBIAPINA, 2007, p. 153) 
Pau de Fumo arranjara emprego de carregador ao encontrar na rua uma chapa com o número 208, tinha esperanças de ter uma vida melhor e passara a ler mais. Podemos perceber no diálogo entre pai e filho que a influencia do senso crítico de Pau de Fumo sobre o amigo Negro Parente fazia-se patente, o último também incorporara um senso mais crítico da realidade, tanto que incentivou o filho Antonino a aprender a ler para conseguir mudar de vida.

O episódio trágico da morte de Genoveva, esposa de Pau de Fumo, pode ser considerado como um marco na vida do protagonista. A mulher suicidara diante de tantos dissabores na vida. Pau de Fumo, a partir desse momento, repensa seus conceitos sobre Deus e a dura vida que todos levavam. Nota-se um personagem mais ameno, menos revoltado, como se passasse a compreender o mundo que o cercava. Devido às leituras e a dura condição social na qual era inserido, outrora passara a questionar Deus e a religião. Com o suicídio da esposa, passa a se sentir mais humano e frágil, a perceber que o homem nada pode contra os desígnios da vida. Pode-se afirmar que nesse momento o protagonista atinge um "equilíbrio crítico" sobre a vida.

Minha velha não mais continua cantando na terra. Foi fazer coro com os anjos no Reino de Deus. (Voltei a acreditar em Deus. Se não acreditar nEle, em quem é que se pode acreditar no mundo?). Enforcou-se, naquela mangueira grande que fica lá no fim da Palha de Arroz para as bandas da Usina (IBIAPINA, 2007, p. 186).

$\mathrm{Na}$ passagem acima temos um trecho de uma carta que Pau de Fumo escreveu para seu melhor amigo Parente que em busca de melhores condições de vida deixou Teresina em direção ao sul do país. Nessa carta, temos a comprovação da transformação do personagem Pau de Fumo, bem como mais um link entre ficção e história quando, em outra passagem da carta, o protagonista menciona que um estudante iria escrever um romance sobre os incêndios e o bairro Palha de Arroz.

Um estudante me disse que vai escrever um romance sobre os incêndios e o nosso Bairro, onde eu, você, Veva, Ceição e Antonino seremos personagens centrais. (...) Ele mesmo não diz, mas todo mundo aqui sabe que é o primeiro aluno do Liceu velho. Temos feito muitas e bonitas farras. Chama-se Jônatas Nonato de Moraes Farias Itabaiana. Mas ele, que escreve em jornais, só assina mesmo Farias Itabaiana (IBIAPINA, 2007, p. 187). 
Podemos relacionar a figura desse estudante ao próprio autor do romance, que no contexto da obra se ficcionaliza através da personagem mencionada en passant. Farias Itabaiana se constitui também como um personagem símbolo da voz dos desassistidos, como "guardião" daquela memória não oficial colhida possivelmente em diversas conversas com Chico da Benta / Pau de Fumo.

Como último link entre ficção e história podemos selecionar uma das últimas passagens do romance, na qual Pau de Fumo (já sem esperanças de mudar de vida, sem paciência de esperar pelo cumprimento da promessa do amigo Parente que prometera Ihe buscar junto aos outros para que recomeçassem a vida no Sul do país) resolve ele mesmo roubar pela última vez para conseguir financiar a viagem da família. Ao ser descoberto pela Polícia, vai preso e depois deportado para o Maranhão. No decorrer da viagem, com diversos pensamentos desordenados na cabeça, resolve por fim executar o plano de suicídio elaborado há tanto tempo. "(Timon... origem grega. Genitivo plural - plural - das honras. Honra de quê?! De quem?!... Diabo, pra que estudei!?...)" (p. 213). Pau de Fumo finalmente decide-se pelo suicídio soltando a planejada "gargalhada espalhafatosa" e atirando-se nas águas do Parnaíba. O suicídio do protagonista marca a consolidação do símbolo fictício-histórico, a memória perdida, a história viva que se "finda", Pau de Fumo extermina ali a fonte histórica de sua vida e do contexto social no qual estava inserido.

\section{CONCLUSÃO}

O narrador em Palha de Arroz emerge como símbolo de uma voz coletiva que abriga os amplos discursos de um contexto social esquecido pela memória oficial. A partir da obra, é possível sinalizar que seu narrador cumpre uma função de religar os eixos entre ficção e história, demonstrando que os mesmos não se constituem efetivamente distantes. Ao se suicidar, o narrador-personagem da obra finda seu papel: é exterminada a sua memória, a fonte da história do contexto social vivido. Podemos afirmar, diante dos aspectos tratados, que os limites entre ficção e história são frágeis e convergentes consolidando o romance analisado por esse viés como importante instrumento de compreensão da história não-oficial: os 
testemunhos, mesmo que ficcionalizados, do organismo da história vivida no contexto da década de 40 e da Ditadura Vargas.

\section{REFERÊNCIAS}

GAGNEBIN, Jeanne Marie. Memóra, história, testemunho. In BRESCIANI, Stella; NAXARA, Márcia. (Org). Memória e (Res) sentimento. Campinas: UNICAMP, 2001.

IBIAPINA, Fontes. Palha de Arroz. 5쪼 ed. Teresina: Oficina da Palavra, 2007.

POLLAK, Michael. Memória, Esquecimento, Silencio. In: Estudos Históricos, Rio de Janeiro, vol. 2, n. 3, 1989, p. 3-15.

SILVA, Raimunda Celestina Mendes da. História e Ficção em Palha de Arroz. In: Fontes Ibiapina. (Org.). Palha de Arroz. 3를 ed. Teresina: Corisco, 2002, v. 01, p. $215-$ 224. 